\title{
OBTENÇÃO DE BIODIESEL A PARTIR DE ÓLEO DE AMÊNDOA DE MACAÚBA UTILIZANDO ONDAS ULTRASSÔNICAS
}

\author{
S. A. MACHADO ${ }^{1}$ e D. S. GIORDANI ${ }^{1}$ \\ ${ }^{1}$ Universidade de São Paulo, Escola de Engenharia de Lorena - EEL \\ E-mail para contato: dsgiordani@usp.br
}

\begin{abstract}
RESUMO - A tecnologia de ultrassom atualmente vem sendo investigada como uma ferramenta de otimização para produção de biodiesel e tem apresentado resultados bastante satisfatórios. Para este trabalho, inicialmente o óleo de amêndoa de macaúba foi submetido à etapa de esterificação nas condições de $2 \% \mathrm{~m} / \mathrm{m}$ de $\mathrm{H}_{2} \mathrm{SO}_{4}$, razão molar óleo:etanol de $1: 9$ e temperatura de $50^{\circ} \mathrm{C}$ por $2 \mathrm{~h}$. Nesta etapa o índice de acidez do óleo foi reduzido de $19 \mathrm{mgKOH} / \mathrm{g}$ para 1,82 $\mathrm{mgKOH} / \mathrm{g}$ possibilitando a aplicação da etapa de transesterificação alcalina. Para o estudo da catálise básica foi utilizado o planejamento fatorial $2^{2}$ com réplicas no ponto central, no processo foi avaliada a razão molar óleo:etanol e a concentração de catalisador. As reações foram processadas em banho ultrassônico $600 \mathrm{~W}$ e $20 \mathrm{kHz}$. Os resultados obtidos demostram que as condições que maximizaram o processo de transesterificação em banho ultrassônico foram: $1,5 \% \mathrm{~m} / \mathrm{m}$ de $\mathrm{KOH}$ e razão molar de 1:6 obtendo-se conversões em torno de 99\%. Os resultados mostraram que a aplicação da sonoquímica apresentou como vantagem a alta conversão em ésteres etílicos em um tempo de apenas 10min o que pode gerar uma redução de custos de produção.
\end{abstract}

\section{INTRODUÇÃO}

O Biodiesel é uma fonte de energia renovável e ecologicamente correta obtida a partir de óleos e gorduras. As vantagens do uso do biodiesel são várias, entre elas o fato de ser produzido a partir de fontes renováveis de energia, de não requerer grandes adaptações nos motores a diesel existentes e emissão de um espectro de poluentes em quantidade e qualidade muito menos danosa à natureza (Ramos, 2003).

O processo comumente utilizado é o de transesterificação no qual os triglicerídeos reagem com álcoois de cadeia curta, na presença de um catalisador. Atualmente o biodiesel é predominantemente preparado utilizando catalisadores alcalinos, como metóxidos e hidróxidos de sódio e potássio. No entanto este processo não pode ser utilizado com matérias primas que apresentem um alto teor de ácidos graxos livres. A presença de ácidos graxos em conjunto com catalisadores básicos leva à formação de sabão, dificultando a separação e diminuindo o rendimento da reação (El-Mashad; Zhang; Avena-Bustillos, 2008).

Neste sentido o processo de esterificação associado à transesterificação alcalina pode viabilizar 
a utilização de matérias primas com altos teores de ácidos graxos livres, como óleo de macaúba, e com isso reduzir o custo de produção de biodiesel.

A utilização de ondas ultrassônicas é outra vertente nas pesquisas para melhorar o rendimento e viabilizar o custo de produção deste combustível. A sonoquímca pode ser aplicada a processos que são limitados pela transferência de massa como a transesterificação alcalina de óleos e com isso reduzir o tempo, melhorar a purificação e reduzir o gasto energético (Paiva et al.,2013). Ultrassons referem-se à propagação de ondas mecânicas de pressão, em frequências superiores à faixa audível pelos ouvidos humanos. A energia ultrassônica é capaz de ativar vários mecanismos físicos e químicos do meio por onde se propaga.

Neste trabalho são apresentados os dados referentes ao processo em duas etapas para obtenção de biodiesel a partir de óleo de amêndoa de macaúba com alta acidez. Na primeira etapa foi aplicada à reação de esterificação para diminuição do índice de acidez, na segunda etapa, a reação de transesterificação alcalina foi conduzida em banho ultrassônico. O planejamento de experimentos foi utilizado como ferramenta para avaliar as melhores condições reacionais na etapa de transesterificação alcalina assistida por ultrassom.

\section{MATERIAIS E MÉTODOS}

\subsection{Etapa de Esterificação Ácida}

Para a redução do índice de acidez o óleo de amêndoa de macaúba foi submetido à reação de esterificação ácida em reator de vidro encamisado de 3,5L equipado com um condensador de refluxo, banho termostático e um agitador mecânico. Inicialmente colocou-se $500 \mathrm{~g}$ de óleo de amêndoa com índice de acidez inicial de $19 \mathrm{mg} \mathrm{KOH} / \mathrm{g}$ de óleo. As condições reacionais utilizadas neste ensaio foram $2 \% \mathrm{~m} / \mathrm{m}_{\text {de }} \mathrm{H}_{2} \mathrm{SO}_{4}$, 1:9 razão molar óleo:etanol, temperatura de $50{ }^{\circ} \mathrm{C}$, agitação de $400 \mathrm{rpm}$ e $2 \mathrm{~h}$ de reação. Após o período reacional o meio foi levado a funil de separação e foram feitas sucessivas lavagens com água deionizada até $\mathrm{pH}$ neutro, posteriormente o meio foi seco com sulfato de magnésio anidro e filtrado a vácuo.

\subsection{Reações de Transesterificação Alcalina em Banho Ultrassônico}

Para o estudo das reações de transesterificação assistidas por ondas ultrassônicas foi utilizada uma matriz experimental $2^{2}$ com três réplicas no ponto central. Os níveis e fatores investigados estão apresentados na Tabela 1. 
Tabela 1 - Fatores e níveis adotados na etapa de transesterificação alcalina assistida por ondas ultrassônicas

\begin{tabular}{ccccc}
\hline & Unidade & \multicolumn{3}{c}{ Níveis } \\
\hline Fatores & & -1 & 0 & 1 \\
Concentração de KOH (A) & $\% \mathrm{~m} / \mathrm{m}$ & 1,0 & 1,5 & 2,0 \\
Razão molar óleo/etanol (B) & Molar & $1: 4$ & $1: 6$ & $1: 8$ \\
\hline
\end{tabular}

As reações de transesterificação alcalina assistidas por ondas ultrassônicas foram realizadas em banho ultrassônico $(600 \mathrm{~W}, 20 \mathrm{kHz})$ utilizando $20 \mathrm{~g}$ de óleo de amêndoa de macaúba previamente submetido à etapa de esterificação ácida.

Em um erlenmeyer equipado com condensador foi preparada a solução de etóxido misturando quantidades adequadas de álcool etílico anidro e catalisador, de acordo com a matriz de planejamento experimental, sob agitação magnética moderada durante $20 \mathrm{~min}$ a $40^{\circ} \mathrm{C}$. A cuba do banho ultrassônico foi preenchida com $300 \mathrm{~mL}$ de água destilada à temperatura ambiente, em seguida o erlenmeyer contendo os reagentes foi posicionado no seu interior e equipado com condensador de refluxo. Não houve controle de temperatura e o tempo reacional foi fixado em $20 \mathrm{~min}$.

Concluída a reação os produtos reacionais foram colocados em funil de decantação e foram adicionados $100 \mathrm{~mL}$ de água deionizada para separação gravimétrica das fases contendo o glicerol (inferior) e fase contendo os ésteres etílicos (superior). Após a separação, a fase superior contendo os ésteres etílicos foi submetida a lavagens com alíquotas de $50 \mathrm{~mL}$ de água deionizada, sendo adicionados entre a primeira e a segunda lavagem $50 \mathrm{~mL}$ de hexano. Os ésteres isolados foram submetidos à secagem com sulfato de magnésio anidro, seguido de filtração a vácuo e para finalizar o meio reacional foi levado ao rotaevaporador por $1 \mathrm{~h}$ a temperatura de $75^{\circ} \mathrm{C}$.

As amostras foram então analisadas em um espectrômetro VARIAN modelo MERCURY (300MHz). A metodologia de quantificação de conversão de ésteres etílicos foi a desenvolvida por Garcia (2006).

\subsection{Caracterização dos Ésteres Etílicos Provenientes do Óleo de Amêndoa de Macaúba (EEAM)}

A caracterização dos ésteres etílicos foi realizada em termos das seguintes propriedades: índice de acidez, teor de glicerol livre e ligado, viscosidade absoluta e densidade.

O índice de acidez foi determinado por titrimetria segundo metodologia AOCS Ti 1c-64. Os teores de glicerol livre e ligado foram determinados pelo método Ca 14-56 da AOCS (AMERICAN OIL CHEMISTS' SOCIETY, 2004).

Os valores de densidade foram determinados utilizando um densímetro digital Modelo DMA $35 \mathrm{~N}$ EX (Anton Paar). As medidas foram feitas à temperatura de $15^{\circ} \mathrm{C}$, empregando-se $2,0 \mathrm{~mL}$ de amostra e os valores da viscosidade absoluta em função da taxa de deformação foram medidos em 
viscosímetro Brookfield Modelo LVDVIII (Brookfield Viscometers Ltd, Inglaterra) empregando o cone $\mathrm{CP}$ 42. As medidas foram feitas a $40{ }^{\circ} \mathrm{C}$, empregando aproximadamente $0,5 \mathrm{~mL}$ de amostra.

\section{RESULTADOS E DISCUSSÕES}

\subsection{Etapa de Esterificação Ácida}

A etapa de esterificação ácida reduziu o índice de acidez para 1,82 $\mathrm{mgKOH} / \mathrm{g}$ e resultou em uma conversão percentual de ésteres etílicos (\%CEE) de 19,90\%. Segundo literatura, a redução do índice de acidez a valores de $2 \mathrm{mgKOH} / \mathrm{g}$ de óleo possibilitam a aplicação da reação de transesterificação alcalina sem prejudicar o rendimento e a separação do produto (Zhang e Jiang 2008)

\subsection{Reações de Transesterificação Alcalina em Banho Ultrassônico}

A etapa de transesterificação alcalina em ultrassom foi realizada de acordo com uma matriz de experimentos $2^{2}$ e os experimentos foram feitos de forma aleatória. Na Tabela 2 estão apresentados os valores \%CEE na etapa de transesterificação alcalina assistida por banho ultrassônico e o \%CCE total nas duas etapas. Para análise estatística foi utilizada a Conversão de ésteres etílicos obtidos somente na etapa de transesterificação.

Tabela 2 - Matriz de planejamento experimental $2^{2}$ da etapa de transesterificação alcalina assistida pelas ondas ultrassônicas

\begin{tabular}{|c|c|c|c|c|c|}
\hline Ensaios & $\begin{array}{c}(\mathbf{A}) \\
\mathbf{\%} \mathbf{m} \mathbf{m} \mathbf{~ K H}\end{array}$ & $\begin{array}{c}(\mathbf{B}) \\
\text { Óle:etanol }\end{array}$ & $\begin{array}{c}\text { \% CEE } \\
\text { Etapa de transesterificação }\end{array}$ & $\begin{array}{c}\text { \% CEE } \\
\text { Total }\end{array}$ \\
\hline 1 & 1,0 & $1: 4$ & 27,94 & 47,84 \\
\hline 2 & 2,0 & $1: 4$ & 56,32 & 76,22 \\
\hline 3 & 1,0 & $1: 8$ & 75,78 & 95,68 \\
\hline 4 & 2,0 & $1: 8$ & 77,15 & 97,05 \\
\hline 5 & 1,5 & $1: 6$ & 78,66 & 98,56 \\
\hline 6 & 1,5 & $1: 6$ & 80,08 & 99,98 \\
\hline 7 & 1,5 & $1: 6$ & 78,92 & 98,82 \\
\hline
\end{tabular}

Análise estatística da reação de transesterificação alcalina em ultrassom: De acordo com a análise do Gráfico de Pareto (Figura 1) observa-se que os fatores concentração de catalisador (KOH) e razão molar óleo:etanol, bem como a interação entre eles foram significativas na transesterificação alcalina em banho ultrassônico. 


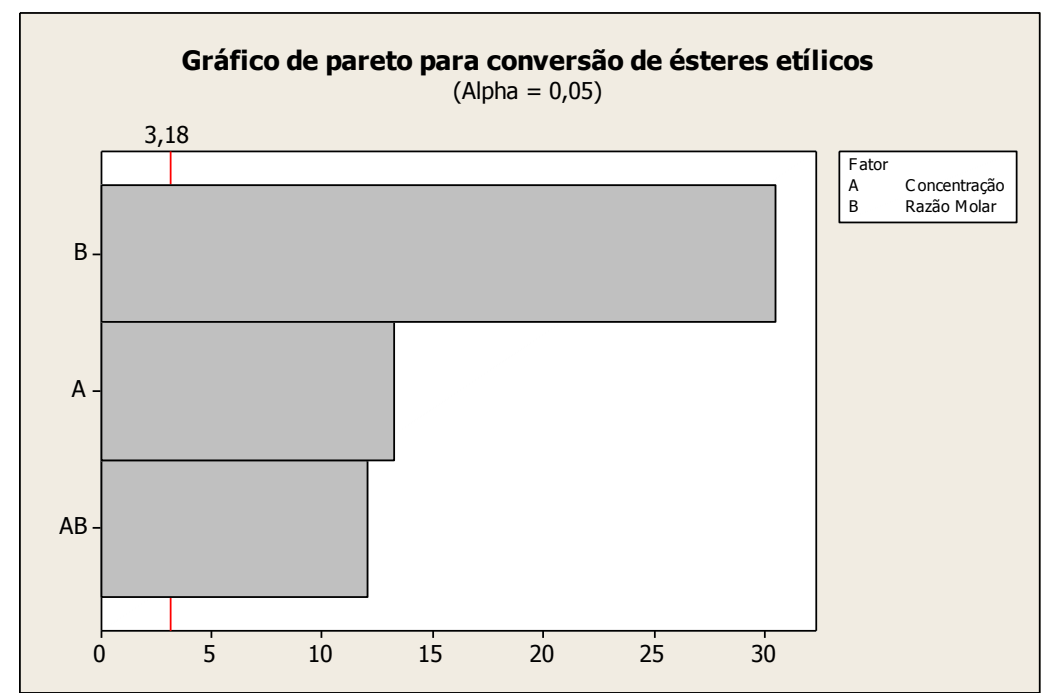

Figura 1 - Gráfico de Pareto para conversão de ésteres etílicos em banho ultrassônico

Para avaliar os níveis dos fatores a serem adotados visando maximizar a conversão de ésteres etílicos, foram analisados dos gráficos dos efeitos principais (Figura 2a) e das interações (Figura 2b).

Com a análise das figuras observa-se que os níveis dos fatores que maximizam a conversão de ésteres etílicos são concentração de catalisador $1,5 \% \mathrm{~m} / \mathrm{m}$ e razão molar 1:6 que são as condições reacionais do ponto central. Os níveis estimados para este planejamento foram idênticos aos encontrados em estudos anteriores para transesterificação alcalina com agitação mecânica (Machado et al., 2012). Entretanto, cabe ressaltar que os experimentos conduzidos em banho ultrassônico foram conduzidos em 20 min de reação e, além disso, não houve controle de temperatura sendo que o único aquecimento foi ocasionado pela aplicação das ondas ultrassônicas no sistema.

Estes resultados indicam que apesar da reação em banho ultrassônico ter acelerado a reação, não influenciou nas interações entre os fatores estudados.
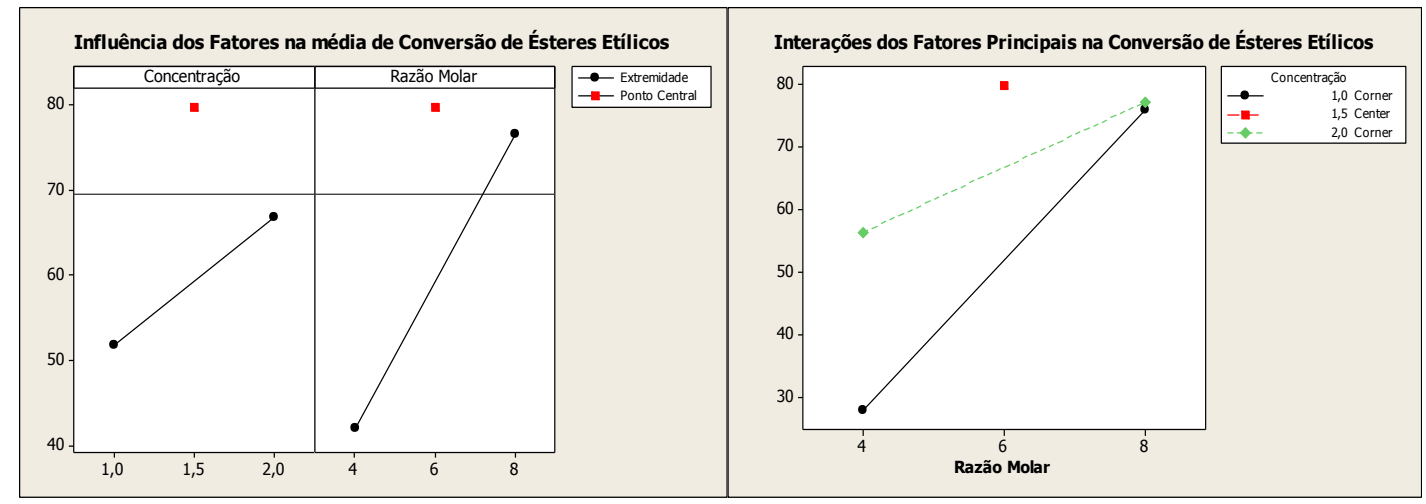

Figura 2 - (a) Gráfico da influência dos fatores na média de conversão de ésteres etílicos em banho ultrassônico; (b) Gráfico das interações dos fatores principais na conversão de ésteres etílicos em banho ultrassônico. 
Através da análise estatística foi possível prever um modelo linear para a reação de transesterificação alcalina em banho ultrassônico. O modelo matemático está apresentado na Equação 1 e apresentou um $\mathrm{R}^{2}$ de 0.9963 . O modelo matemático encontrado não demonstra indícios de falta de ajuste e explica $97,82 \%$ das variações em torno da média. O desvio padrão (s) determinado através das réplicas realizadas no ponto central foi de 1,12652 .

$$
\% C E E=59,297+7,434(A)+17,168(B)-6,752(A B)
$$

Depois de determinadas as melhores condições reacionais para transesterificação alcalina em banho foram realizados novos experimentos nos tempos de 5, 10, 15 e 20 min (Tabela 3). Com estes experimentos foi possível verificar que a reação foi concluída em $10 \mathrm{~min}$.

Paiva et al.(2013) também constatou em seu trabalho que a aplicação de ondas ultrassônicas reduziu consideravelmente o tempo de reação. Essa redução pode ser atribuída à intensa transferência de massa promovida pela cavitação, o que implica em um menor tempo para a difusão dos reagentes.

Tabela 3- Análise do tempo de conversão de ésteres etílicos em banho ultrassônico e sonda ultrassônica.

\begin{tabular}{|c|c|}
\hline Tempo reacional (min) & \% CEE Total \\
\hline $\mathbf{5}$ & 79,85 \\
\hline $\mathbf{1 0}$ & 99,61 \\
\hline $\mathbf{1 5}$ & 99,98 \\
\hline $\mathbf{2 0}$ & 98,92 \\
\hline
\end{tabular}

\subsection{Caracterização dos Ésteres Etílicos Provenientes do Óleo de Amêndoa de Macaúba (EEAM)}

Comparando-se os resultados obtidos na análise dos EEAM com as especificações da ANP observa-se que os parâmetros analisados estão dentro dos padrões estabelecidos pela agência (Tabela 4). Os teores de glicerina livre indicam que o processo de purificação foi eficiente. Altas concentrações de glicerina no biodiesel provocam problemas relacionados com formação de depósitos, entupimento dos bicos injetores do motor e emissões de aldeídos (LOBO; FERREIRA, 2009). A glicerina total é a soma da glicerina livre e da glicerina combinada. A glicerina combinada inclui mono-, di- e triglicerídeos provenientes de reações incompletas. Desta maneira, a análise deste fator fornece um indício da eficiência do processo de conversão. Neste trabalho, o teor encontrado de glicerina total foi inferior ao estabelecido pela norma indicando que o processo em duas etapas foi eficiente na conversão do óleo a biodiesel.

A massa específica foi obtida a $15^{\circ} \mathrm{C}$, mas a norma brasileira estabelece que esta medida seja realizada a $20^{\circ} \mathrm{C}$. Cabe ressaltar que a massa específica decresce com o aumento da temperatura e, portanto, presume-se que mesmo com a variação de temperatura o valor esteja compreendido entre os 
limites estabelecidos pela ANP (Tabela 4).

Tabela 4 - Caracterização dos ésteres etílicos de amêndoa de macaúba (EEAM)

\begin{tabular}{|c|c|c|c|}
\hline Parâmetro & Unidade & EEAM & ANP 7 \\
\hline Índice de Acidez & $\mathrm{mgKOH} / \mathrm{g}$ & 0,19 & $\leq 0,5$ \\
\hline Glicerina total & $\% \mathrm{~m} / \mathrm{m}$ & 0,2430 & $\leq 0,25$ \\
\hline Glicerina livre & $\% \mathrm{~m} / \mathrm{m}$ & 0,01 & $\leq 0,02$ \\
\hline Viscosidade absoluta $\left(40^{\circ} \mathrm{C}\right)$ & $\mathrm{cP}$ & 3,14 & -- \\
\hline Massa específica $\left(15^{\circ} \mathrm{C}\right)$ & $\mathrm{g} / \mathrm{cm}^{3}$ & 0,87 & $0,85-0,90$ \\
\hline Viscosidade cinemática $\left(40^{\circ} \mathrm{C}\right)$ & $\mathrm{cSt}$ & 3,61 & $3,0-6,0$ \\
\hline
\end{tabular}

\section{CONCLUSÕES}

O processo como um todo, além de viabilizar a utilização do óleo de amêndoa com alta acidez reduziu consideravelmente o tempo de reação.

A etapa de esterificação utilizando catalisador ácido foi eficiente na redução do índice de acidez. O índice de acidez foi reduzido de $19 \mathrm{mg} \mathrm{KOH} / \mathrm{g}$ para 1,82 mg KOH/g. Já na etapa de transesterificação alcalina em banho ultrassônico a análise estatística indicou que as condições reacionais ótimas para o processo são $1,5 \% \mathrm{~m} / \mathrm{m}$ de $\mathrm{KOH}$ e razão molar óleo etanol 1:6 em $10 \mathrm{~min}$ atingindo conversões em torno de $99 \%$.

As caracterizações dos ésteres etílicos demonstram que o produto atende às especificações da ANP e, portanto, confirmam a macaúba como possível matéria prima para produção de biodiesel.

\section{REFERÊNCIAS}

EL-MASHAD, H.M.; ZHANG,R.; AVENA-BUSTILLOS, R. J. A two-step process for biodiesel production from salmon oil. Biosystems Eng., v.99, p.220-227, 2008

GARCIA, C.M. Transesterificação de óleos vegetais. 2006.136f. Dissertação (Mestrado) - Instituto de Química, Universidade Estadual de Campinas, Campinas, 2006.

LÔBO, I. P.; FERREIRA, S. L. C. Biodiesel: parâmetros de qualidade e métodos analíticos. Química Nova, v. 32, p. $1596-1608,2009$.

MACHADO, S.A. Estudo da produção de biodiesel a partir de óleo de amêndoa de macaúba utilizando agitação convencional e ondas ultrassônicas. In: XIX Congresso Brasileiro de Engenharia Química, 2012, Búzios, RJ.

PAIVA, E. J.M. et al. Non-edible babassu oil as a new source for energy production-a feasibility 
transesterification survey assisted by ultrasound. Ultrasonics Sonochemistry, v.20, p.833-838, 2013.

RAMOS, L. P. et al. Biodiesel: Um Projeto de Sustentabilidade Econômica e Sócio, Ambiental para o Brasil. Biotecnologia, Ciência e Desenvolvimento. Revista Biotecnologia Ciência \& Desenvolvimento, v.31, p.28-37, 2003

STAVARACHE, C.; VINATORU, M.; MAEDA, Y. Ultrasonic versus silent methylation of vegetable oils. Ultrasonics Sonochemistry, v.13, p.401-407, 2006

ZHANG J.;JIANG L. Acid-catalyzed esterification of Zanthoxylum bungeanum seed oil with high free fatty acids for biodiesel production. Bioresource Tech, v.99, p.8995-8998, 2008. 